\title{
Socio-demographic and medical predictors of rheumatic heart disease in a low-risk population
}

\author{
Oksana Boyarchuk', Roman Komorovsky², Tetiana Kovalchuk³ ${ }^{3}$ Olha Denefil ${ }^{4}$ \\ 'Department of Children's Diseases and Pediatric Surgery, I. Horbachevsky Ternopil State Medical University, Ternopil, Ukraine \\ ${ }^{2}$ Department of Internal Medicine \#2, I. Horbachevsky Ternopil State Medical University, Ternopil, Ukraine \\ ${ }^{3}$ Department of Pediatrics \#2, I. Horbachevsky Ternopil State Medical University, Ternopil, Ukraine \\ ${ }^{4}$ Department of Pathological Physiology, I. Horbachevsky Ternopil State Medical University, Ternopil, Ukraine
}

\section{ABSTRACT}

Introduction: The risk factors for development of rheumatic heart disease (RHD) are well described for highrisk countries but less well known for low-risk countries, including Ukraine.

Aim of the study: The aim of this study was to investigate the role of demographic, social, and medical risk factors for development of RHD in a low-risk area (Western Ukraine) with an annual incidence of acute rheumatic fever (ARF) of 1 per 100,000 population.

Material and methods: Between 2007-2014, 132 subjects aged 8-17 years from three medical centres were enrolled in the study. Of them, 78 patients developed RHD either after ARF ( $n=48,61.5 \%$ ) or subclinically $(n=30,38.5 \%)$ and were selected as cases. The remaining 54 subjects, who had ARF but did not develop RHD during follow-up, were defined as controls. The median follow-up period of subjects after ARF was five years (range 3-10 years). Demographic, social and medical factors were linked to development of RHD by univariate and multivariable regression modelling.

Results: At the univariate level, rural population and unemployed parents were found to be at significantly higher risk of development of RHD. Among medical risk factors, chronic infections, recurrent ARF, and lack or irregularity of secondary prevention were found to be significant determinants of RHD. In multivariable analysis, living in a rural area $(\mathrm{OR}=6.85,95 \% \mathrm{CI}=2.39-19.67)$, recurrent $\mathrm{ARF}(\mathrm{OR}=37.18,95 \%$ $\mathrm{CI}=4.21-328.34)$, and lack of secondary prevention of $\mathrm{ARF}(\mathrm{OR}=4.10,95 \% \mathrm{CI}=1.04-16.14)$ were found to be significant predictors for development of RHD.

Conclusions: The present study has shown that in a low-risk population, living in a rural area, recurrent ARF, and lack of secondary prevention independently predict the development of RHD.

\section{KEY WORDS:}

rheumatic heart disease, risk factors, low-risk population.

\section{INTRODUCTION}

Acute rheumatic fever (ARF) is a diffuse autoimmune disease associated with abnormal response to group A streptococcal infection and primarily involving heart, joints, skin, and brain [1]. Rheumatic carditis may lead to the development of rheumatic heart disease (RHD) [2, 3].
There is a clear downward trend of the ARF incidence in the world, but the prevalence of RHD is still high, with a tendency to increase in some regions of the world [4]. Differences in prevalence of RHD are associated with economic and social inequality [5]. According to the revision of the Jones criteria (2015) for the diagnosis of ARF, major and minor criteria were defined for the low-risk,

\section{ADDRESS FOR CORRESPONDENCE:}

Tetiana Kovalchuk, Department of Paediatrics \#2, I. Horbachevsky Ternopil State Medical University, Maidan Voli, 1, 46001 Ternopil, Ukraine, e-mail: tetianakovalchuk@gmail.com 
moderate-risk, and high-risk populations [6]. The highest incidence of ARF is observed in sub-Saharan Africa, South Asia, and Australasia [7-9]. Overcrowding, poor housing conditions and hygiene, undernutrition associated with poverty, and economic disadvantage are well known risk factors for $\mathrm{ARF}$ and RHD in moderate-risk and high-risk countries [10-13].

The incidence of ARF in Ukraine, including its Western region, is currently decreasing, and over the past three years it has not exceeded 1 per 100,000 children [14]. Therefore, Ukraine is considered to be a low-risk country for ARF. The prevalence of RHD appears to be decreasing as well, although the rates are still high: 398.3 per 100,000 people of all ages in Ukraine in 2012, with the highest rates in the Western region (542.1 per 100,000 people of all ages) [15].

ARF develops in only a small number of children after A-streptococcal infection [16]. RHD is the most serious sequel of ARF and developed in $40-50 \%$ of ARF patients [17]. It has been established that recurrent rheumatic fever increases the risk of RHD [1-3]. However, the role of other factors that contribute to the development of RHD is not clearly defined. In addition, the risk factors for RHD development are well described for high-risk countries but less well known for low-risk countries, including Ukraine.

The aim of this study was to investigate the role of demographic, social, and medical risk factors for development of RHD in a low-risk area (Western Ukraine) with an annual incidence of ARF of 1 per 100,000 population.

\section{MATERIAL AND METHODS}

This is a case control study in which RHD cases and controls (children who had ARF but in whom RHD did not develop) were assessed for environmental and medical risk factors. A total of 132 patients (78 cases and 54 controls) aged 8 to 17 years participated in the study. All patients (cases and controls) were from three regions of Western Ukraine: Ternopil (79 children), Khmelnytskyi ( 25 children), and Rivne (28 children). The survey was conducted from 2007 to 2014 during the inpatient treatment of children.

Cases and controls were defined as having RHD/no RHD according to World Health Organisation criteria [1] and World Heart Federation criteria [2] for echocardiographic diagnosis of RHD. ARF was diagnosed according to the Jones criteria [1].

RHD was diagnosed in 78 patients (cases) by careful clinical and echocardiographic Doppler examination. Subclinical rheumatic carditis was diagnosed in children having rheumatic cardiac lesions but no history of ARF, after exclusion of other potential causes (congenital heart disease, cardiomyopathy, infective endocarditis, etc.). In 54 patients with a history of ARF careful clinical and echo- cardiographic Doppler examination did not reveal any cardiac lesions. These patients were considered as controls.

The survey of cases and controls was performed. It included a questionnaire containing the following parameters: age, gender, living conditions (residence urban or rural), employment status, family status (complete or incomplete families), and number of people per dwelling unit. The number of people per dwelling unit was determined to define overcrowding $[18,19]$.

The medical risk factors were also detected: family history, recurrent rheumatic fever, and lack or irregularity of secondary prevention. If more than one dose of benzathine penicillin was delayed or missed during a sixmonth period, it was classified as irregularity of secondary prevention. A separate block of questions concerned patient adherence to secondary prevention of ARF. Questions about recurrent rheumatic fever and secondary prevention were given only to patients with a history of ARF $(n=48)$. The survey was performed as a face-to-face interview of each patient during the period of hospitalisation, after obtaining informed consent.

Chronic infections and autonomic nervous system disorders, which can affect the course and outcome of RHD, were also recorded. Chronic infections were diagnosed on the basis of a careful survey and clinical examination of the patients. Autonomic nervous system was evaluated based on complaints, physical examination, and spectral analysis of heart rate variability.

The results were analysed using standard procedures with the Statistica StatSoft 6.0 software package. Values are expressed as mean \pm standard deviation (SD) for continuous variables and $n$ (percentages) for categorical variables. Unpaired t-test was used to compare continuous variables between the groups, and $\chi^{2}$ test was used to compare proportions. First, univariate analysis was performed to detect the factors having a significant relationship with development of RHD. Odds ratios (OR) were computed with $95 \%$ confidence interval (CI). Then, multivariate logistic regression analysis was performed using a backward stepwise procedure. For all tests, $p$-values $<0.05$ were considered significant.

Ethical approval for the study was obtained from the scientific Ethics Committee of Ternopil State Medical University. The parents of the children participating in this study signed their informed consent. The study conformed to the principles outlined in the declaration of Helsinki.

\section{RESULTS}

Cardiac involvement based on the type of valvular lesions in children with RHD is presented in Table 1. Mitral regurgitation (MR) was the predominant valvular lesion in children with RHD. The demographic characteristics of the study subjects are shown in Table 2.

Among the cases, the residents of rural areas predominated (50 [64.1\%] vs. 28 [35.9\%], $\chi^{2}=4.17$, 
$p=0.0411)$. Subclinical rheumatic carditis was diagnosed in $30(38.5 \%)$ cases, and $48(61.5 \%)$ cases had a history of ARF. The mean period after ARF was $5.80 \pm 3.16$ years, ranging from 1 to 13 years. In most cases $(n=30$ [62.5\%]) RHD developed within the first five years after ARF, often within the first three years $(n=22[45.8 \%])$.

Among the controls, the urban residents predominated (43 [79.6\%] vs. 11 [20.4\%], $\left.\chi^{2}=13.16, p=0.0003\right)$. The mean period after ARF in the controls was $4.96 \pm 2.63$ years, ranging from three to 10 years. In the majority of controls $(n=33[61.1 \%])$ this period ranged from three to five years.

Although the cases of RHD appeared to be slightly older, there were no significant differences between the cases and controls in terms of gender, frequency of incomplete families, and number of people per house $(p>0.05)$ (Table 2).

Patients from urban areas were more often from the control group; therefore, patients from rural areas were more often from the case group. In the case group the number of unemployed parents was higher than in the control group.

Among medical risk factors for RHD, chronic infections were more prevalent in the cases as compared with the controls (Table 3).

Chronic infections manifested most frequently as nasopharyngeal infections: chronic tonsillitis was found in $10(12.8 \%)$ cases and in one (1.9\%) control, and chronic pharyngitis was diagnosed in five $(6.4 \%)$ cases. Other infections were uncommon and diagnosed as chronic
TABLE 1. Cardiac involvement of the study subjects

\begin{tabular}{|l|c|c|}
\hline \multirow{2}{*}{ Type of cardiac involvement } & \multicolumn{2}{|c|}{ Cases of RHD $(n=78)$} \\
\cline { 2 - 3 } & $n$ & $\%$ \\
\hline MR & 42 & 53.9 \\
\hline MR, MS & 4 & 5.1 \\
\hline AR & 4 & 5.1 \\
\hline AR, AS & 4 & 5.1 \\
\hline MR, AR & 21 & 26.9 \\
\hline MR, MS, AR & 2 & 2.6 \\
\hline AR, AS, MR & 1 & 1.3 \\
\hline
\end{tabular}

RHD - rheumatic heart disease, MR - mitral regurgitation, $M S$ - mitral stenosis, AR - aortic regurgitation, AS - aortic stenosis

blepharitis, recurrent bronchitis, chronic pyelonephritis, and dental caries.

Autonomic neurological disorders in children of both groups were manifested by the complaints of headache, stabbing (pinching) pain in the chest, heart rate and blood pressure variability, and hypotension. The frequency of recurrent rheumatic fever was also significantly higher among the cases. In the controls there was only one episode of recurrent rheumatic fever in one patient. Among the cases, a cardiac lesion developed after the third episode of recurrent rheumatic fever in three (6.3\%) patients, after the second recurrence of ARF in four $(8.3 \%)$ patients, and after the first recurrence of ARF in eight $(16.7 \%)$ patients.

TABLE 2. Demographic characteristics of the study subjects

\begin{tabular}{|l|c|c|c|}
\hline Factors & $\begin{array}{c}\text { Cases of RHD } \\
n=78(\%)\end{array}$ & $\begin{array}{c}\text { Controls } \\
n=54(\%)\end{array}$ & $p$-value \\
\hline $\begin{array}{l}\text { Age, years (mean } \pm \text { SD) } \\
\text { Gender }\end{array}$ & $15.22 \pm 1.82$ & $14.15 \pm 2.80$ & 0.01 \\
\hline Male & $47(60.3)$ & $34(63.0)$ & 0.8342 \\
\hline Female & $31(39.7)$ & $20(37.0)$ & 0.0075 \\
\hline \begin{tabular}{l} 
Living conditions \\
\hline Urban
\end{tabular} & $28(39.5)$ & & 0.0018 \\
\hline Rural & $50(64.1)$ & $11(20.4)$ & 0.2867 \\
\hline \begin{tabular}{l} 
Employment status \\
\hline Employed
\end{tabular} & $51(65.4)$ & $47(87.0)$ & 0.0284 \\
\hline Unemployed & $27(34.6)$ & $7(13.0)$ & 0.9174 \\
\hline Family status & & & 0.8224 \\
\hline Complete families & $59(75.6)$ & $42(77.8)$ & $12(22.2)$ \\
\hline Incomplete families & $19(24.4)$ & & 0.8863 \\
\hline Number of people per dwelling unit & $64(82.1)$ & $46(85.2)$ & 0.6873 \\
\hline$<6$ & $14(17.9)$ & $8(14.8)$ & \\
\hline$\geq 6$ & & & \\
\hline
\end{tabular}

RHD - rheumatic heart disease; data are presented as $n$ (\% of patients) unless otherwise specified 
TABLE 3. Prevalence of medical risk factors in the study subjects

\begin{tabular}{|l|c|c|c|}
\hline Factors & $\begin{array}{c}\text { Cases of RHD } \\
n=78(\%)\end{array}$ & $\begin{array}{c}\text { Controls } \\
n=54(\%)\end{array}$ & $p$-value \\
\hline Family history of RHD & $15(19.2)$ & $6(11.1)$ & 0.2821 \\
\hline Chronic infections & $23(29.5)$ & $4(7.4)$ & 0.0103 \\
\hline Autonomic neurological disorders & $19(24.4)$ & $8(14.8)$ & 0.2736 \\
\hline Recurrent rheumatic fever & $15(31.3)$ & $1(1.9)$ & 0.0005 \\
\hline Lack of secondary prevention & $12(25.0)$ & $3(5.6)$ & 0.0172 \\
\hline Irregularity of secondary prevention & $19(39.6)$ & $9(16.7)$ & 0.0511 \\
\hline
\end{tabular}

RHD - rheumatic heart disease; data are presented as $n$ (\% of patients)

The lack of secondary prevention of streptococcal infections was more common in the cases than in the controls. The main reason for lack of secondary prevention was the low compliance of prophylaxis (20.5\%). Allergic reactions to penicillin occurred in $3.9 \%$ of cases $(p=0.0099)$.

Univariate and multivariate logistic regression analyses of environmental and medical variables predicting the development of RHD are shown in Tables 4 and 5. According to univariate analyses, significantly more favourable conditions for the development of RHD were found in the rural population $(\mathrm{OR}=6.98,95 \% \mathrm{CI}=3.11-15.66)$. In the cases, the number of unemployed parents was greater than in the controls $(\mathrm{OR}=3.55,95 \% \mathrm{CI}=1.42-8.93)$ (Table 3).

In univariate analysis of medical risk factors for RHD, chronic infections $(\mathrm{OR}=5.22,95 \% \mathrm{CI}=1.69-16.16)$ and recurrent rheumatic fever $(\mathrm{OR}=24.09,95 \% \mathrm{CI}=$ 3.04-190.99) were more common in the cases than in the controls (Table 4). Risk of development of RHD was revealed after the first episode of recurrent rheumatic fever $(\mathrm{OR}=10.6,95 \% \mathrm{CI}=1.27-88.23, p=0.01)$.

The lack of secondary prevention of streptococcal infections and its irregularity was more common in the cases than in the controls $(\mathrm{OR}=5.67,95 \% \mathrm{CI}=1.49-21.54$ and $\mathrm{OR}=3.28,95 \% \mathrm{CI}=1.31-8.22$, respectively).

The multivariate logistic regression analysis showed that living in a rural area, recurrent rheumatic fever, and lack of secondary prevention are significant determinants of RHD in children.

\section{DISCUSSION}

The study showed that in Ukraine living conditions are important environmental determinants of RHD. Rural residence is a risk factor for RHD. Overcrowding (num-

TABLE 4. Univariate and multivariate logistic regression analyses of environmental variables predicting the presence of rheumatic heart disease

\begin{tabular}{|l|c|c|c|c|}
\hline \multirow{2}{*}{ Variables } & \multicolumn{2}{|c|}{ Univariate analysis } & \multicolumn{2}{c|}{ Multivariate analysis } \\
\cline { 2 - 5 } & OR $(95 \% \mathrm{Cl})$ & $p$-value & OR (95\% Cl) & $p$-value \\
\hline Female gender & $1.12(0.55-2.29)$ & 0.89 & - & $<$ \\
\hline Living in a rural area & $6.98(3.11-15.66)$ & $<0.001$ & $6.85(2.39-19.67)$ & $<0.001$ \\
\hline Unemployed status & $3.55(1.42-8.93)$ & 0.009 & - & - \\
\hline Incomplete family status & $1.13(0.49-2.57)$ & 0.92 & - & - \\
\hline Number of people per dwelling unit $(\geq 6)$ & $1.26(0.49-3.25)$ & 0.81 & - & - \\
\hline
\end{tabular}

CI- confidence interval, OR - odds ratio

TABLE 5. Univariate and multivariate logistic regression analyses of medical variables predicting the presence of rheumatic heart disease

\begin{tabular}{|l|c|c|c|c|}
\hline \multirow{2}{*}{ Variables } & \multicolumn{2}{|c|}{ Univariate analysis } & \multicolumn{2}{c|}{ Multivariate analysis } \\
\cline { 2 - 5 } & OR $(95 \% \mathrm{Cl})$ & $p$-value & OR (95\% CI) & $p$-value \\
\hline Family history & $1.90(0.69-5.28)$ & 0.31 & - & - \\
\hline Chronic infections & $5.22(1.69-16.16)$ & 0.004 & - & - \\
\hline Autonomic neurological disorders & $1.85(0.74-4.61)$ & 0.26 & - & 0.001 \\
\hline Recurrent rheumatic fever & $24.09(3.04-190.99)$ & 0.013 & $37.18(4.21-328.34)$ & 0.04 \\
\hline Lack of secondary prevention & $5.67(1.49-21.54)$ & 0.01 & $4.10(1.04-16.14)$ & - \\
\hline Irregular secondary prevention & $3.28(1.31-8.22)$ & 0.02 & - & - \\
\hline
\end{tabular}

CI-confidence interval, OR - odds ratio 
ber of people per house) was not found to be a significant risk factor for development of RHD. Gender, age, family status (complete or incomplete families), and employment status of parents also did not have a significant influence on the development of RHD.

Some studies from developing countries found urban residence to be a risk factor for RHD, due to overcrowding [10], while rural residence was associated with a low risk of RHD. Other studies, on the contrary, showed a higher prevalence of RHD in rural residents [17, 20]. In countries with high prevalence of RHD, overcrowding is still the dominant risk factor for both ARF and RHD [13]. Little difference between RHD patients and controls regarding overcrowding was found in research from Fiji [21]. Another study showed that interaction exists between overcrowding and distance to the nearest health centre; the effect of overcrowding on the risk of acquiring RHD increases with every kilometre from the nearest health centre [13].

According to our findings, the increased risk of RHD in rural residents may be associated with worse social conditions as compared with urban residents. Rural residence is often associated general overcooling (hypothermia) of children, lower accessibility of quality healthcare due to large distance to the nearest health centre, and low alertness about the importance of preventive measures. An Australian study has shown that RHD incidence was higher not only among indigenous people as compared with non-indigenous population, but also among female patients [9].

The role of unemployment as a risk factor for RHD was reported [21], although in some works its significant influence on the development of the disease was not shown [10]. At the same time, the increased risk of RHD in overcrowding associated with unemployment was established [13].

Among the medical risk factors for RHD in patients with a history of ARF, recurrent rheumatic fever is of utmost importance, and the risk significantly increases after the first recurrence. Recurrent rheumatic fever is well known as a risk factor for RHD [1, 2, 10], and our study confirmed its importance in the development of RHD in Ukraine.

The lack of secondary prevention is also a significant risk factor for RHD. Low patient compliance to secondary prevention may be associated with the parents' and patients' lack of awareness of the problem. Hence it is very important to focus more on parents' education. Low education of mothers was a significant predictor of increased risk of RHD among the ARF patients in a case-control Bangladesh study [10]. The importance of patients' and their family members' education on ARF, RHD, and prevention was also reported in other publications [22, 23]. Active follow-up of patients with ARF is required for better adherence to long-term prophylaxis, especially is cases of lack or irregularity of secondary prevention. [23]. Effective ARF registers and reduction of pain of benzathine penicillin injections, along with patients' and parents' education, are the key methods for improvement of adherence to secondary prevention [23]. Other studies added strategies to ensure an active recall system, providing holistic care, and involving community health workers for improved delivery of secondary prophylaxis for ARF and RHD [24, 25]. Reasons for low adherence to secondary prevention of cardiovascular diseases include poor motivation, forgetfulness, lack of education about medications, complicated regimens, adverse side effects, and limited practical support [26]. In the era of novel technologies, the authors propose to use devices (smartphones, tablets) to encourage patients' responsibility for the use of medications. This will allow the application of computer-based education, mobile phone reminders that potentially improve adherence to secondary prevention [26].

Although lack and irregularity of secondary prevention may be related, our study demonstrated that lack of secondary prevention is an independent predictor for development of RHD.

Regarding family history of ARF and/or RHD, little difference was observed between the cases and the controls, which can play a role in the development of ARF $[4,16]$.

\section{CONCLUSIONS}

This study has shown that in Ukraine living in a rural area, recurrent rheumatic fever, and lack of secondary prevention are significant determinants for RHD in children. These factors are independent predictors for development of RHD. Active follow-up of patients with ARF with an active recall system, and education of patients and their parents with the use of novel technologies may be very useful in improving compliance to long-term prophylaxis.

\section{ACKNOWLEDGEMENTS}

We would like to thank the doctors and the all the medical staff of the regional and city children's hospitals of Ternopil, Khmelnytskyi, and Rivne for their support.

\section{DISCLOSURE}

The authors declare no conflict of interest.

\section{REFERENCES}

1. World Health Organization. Rheumatic Fever and Rheumatic Heart Disease: Report of a WHO Expert Consultation, Geneva, 29 October - 1 November 2001. WHO Technical Report Series 923, 2001.

2. Remenyi B, Wilson N, Steer A, et al. World Heart Federation criteria for echocardiographic diagnosis of rheumatic heart disease: an evidence-based guideline. Nat Rev Cardiol 2012; 9: 297-309.

3. Marijon E, Mirabel M, Celermajer DS, Jouven X. Rheumatic heart disease. Lancet 2012; 379: 953-964. 
4. Seckeler MD, Hoke TR. The worldwide epidemiology of acute rheumatic fever and rheumatic heart disease. Clin Epidemiol 2011; 3: 67-84.

5. Rothenbuhler M, O'Sullivan CJ, Stortecky S, et al. Active surveillance for rheumatic heart disease in endemic regions: a systematic review and meta-analysis of prevalence among children and adolescents. Lancet Glob Health 2014; 2: e717-726.

6. Gewitz MH, Baltimore RS, Tani LY, et al. Revision of the Jones criteria for the diagnosis of acute rheumatic fever in the era of Doppler echocardiography: a scientific statement from the American Heart Association. Circulation 2015; 131: 1806-1818.

7. Carapetis JR, Beaton A, Cunningham M, et al. Acute rheumatic fever and rheumatic heart disease. Nat Rev Dis Primers 2016; 2: 15084.

8. Carapetis JR, Steer AC, Mulholland EK, Weber M. The global burden of group A streptococcal diseases. Lancet Infect Dis 2005; 5: 685-694.

9. Lawrence JG, Carapetis JR, Griffiths K, et al. Acute rheumatic fever and rheumatic heart disease: incidence and progression in the Northern Territory of Australia, 1997 to 2010. Circulation 2013; 128: 492-501.

10. Riaz BK, Selim S, Karim N, et al. Risk factors of rheumatic heart disease in Bangladesh: a case-control study. J Health Popul Nutr 2013; 31: 70-77.

11. Steer AC, Carapetis JR, Nolan TM, Shann F. Systematic review of rheumatic heart disease prevalence in children in developing countries: the role of environmental factors. J Paediatr Child Health 2002; 38: 229-234.

12. Brown A, McDonald MI, Calma T. Rheumatic fever and social justice. Med J Aust 2007; 186: 557-558.

13. Okello E, Kakande B, Sebatta E, et al. Socioeconomic and environmental risk factors among rheumatic heart disease patients in Uganda. PLoS ONE 2012; 7: e43917.

14. Boyarchuk O, Boytsanyuk S, Hariyan T. Acute rheumatic fever: clinical profile in children in western Ukraine. J Med Life 2017; 10: $122-126$.

15. Kovalenko VM, Kornatsky VM. Regional medical and social problems of cardiovascular diseases. Dynamics and analysis. Kyiv 2013: 240.

16. Bryant PA, Robins-Browne R, Carapetis JR, Curtis N. Some of the people, some of the time: susceptibility to acute rheumatic fever. Circulation 2009; 119: 742-753.

17. Paar JA, Berrios NM, Rose JD, et al. Prevalence of rheumatic heart disease in children and young adults in Nicaragua. Am J Cardiol 2010; 105: 1809-1814.

18. World Health Organisation. Average household size. World Health Organisation, 2013.

19. Clauson-Kaas J, Dzikus A, Stephens C, et al. Urban health: human settlement indicators of crowding. Third World Plan Rev 1996; 18: 349-363.

20. Marijon E, Ou P, Celermajer DS, et al. Prevalence of rheumatic heart disease detected by echocardiographic screening. N Engl J Med 2007; 357: 470-476.

21. Dobson J, Steer AC, Colquhoun S, Kado J. Environmental factors and rheumatic heart disease in Fiji. Pediatr Cardiol 2011; 33: 332-336.

22. Joseph N, Madi D, Kumar GS, et al. Clinical spectrum of rheumatic fever and rheumatic heart disease: a 10 year experience in an urban area of South India. N Am J Med Sci 2013; 5: 647-652.

23. Atatoa-Carr P, Lennon D, Wilson N. Rheumatic fever diagnosis, management, and secondary prevention: a New Zealand guideline. N Z Med J 2008; 121: 59-69.

24. Kevat PM, Reeves BM, Ruben AR, Gunnarsson R. Adherence to Secondary Prophylaxis for Acute Rheumatic Fever and Rheumatic Heart Disease: A Systematic Review. Curr Cardiol Rev 2017; 13: 155.
25. Rémond MG, Coyle ME, Mills JE, Maguire GP. Approaches to Improving Adherence to Secondary Prophylaxis for Rheumatic Fever and Rheumatic Heart Disease: A Literature Review with a Global Perspective. Cardiol Rev 2016; 24: 94-98.

26. Cheng K, Ingram N, Keenan J, et al. Evidence of poor adherence to secondary prevention after acute coronary syndromes: possible remedies through the application of new technologies Open Heart 2015; 2: e000166. 